\title{
BREVE GENEALOGIA DA FAMÍLIA CUNHA PEREIRA
}

\author{
Fernando Marcelino Pereira ${ }^{1}$
}

- Enviado em 15/04/2016

- Aprovado em 25/05/2016

\section{RESUMO}

O objetivo deste artigo é descrever e analisar o perfil social e político dos integrantes da família de Francisco Cunha Pereira Filho, diretor-presidente do jornal Gazeta do Povo. Para tal, apresentaremos descrição das gerações da família ratificando a presença de seus membros na esfera pública paranaense. Esta pesquisa tem como objetivo central dar sequência nos estudos sobre as genealogias da classe dominante paranaense.

Palavras-chave: Genealogia. Empresas de Comunicação. Poder.

\section{INTRODUÇÃO}

Poucas famílias controlam a comunicação de massa no Paraná.

Existem famílias de políticos que controlam meios de comunicação local. Em 2011, a Gazeta do Povo publicou matéria chamada "Políticos são donos de $15 \%$ das rádios no PR"² onde revelou que pelo menos 54 emissoras de rádio das 355 com registro no governo federal pertencem a políticos ou familiares. A reportagem identificou que entre os empresários do setor estão exgovernadores, conselheiro do Tribunal de Contas do Estado, secretários de estado, deputados federais e estaduais, prefeitos, ex-prefeitos e vereadores. Ao todo, foram identificados pelo menos 45 donos de rádio que exercem, ou exerceram, cargos eletivos.

\footnotetext{
${ }^{1}$ Graduado em Relações Internacionais pela UNICURITIBA, Mestre em Ciência Política e Doutorando em Sociologia pela UFPR. Membro do Núcleo de Estudos Paranaenses (NEP). Endereço eletrônico: fernandomarcelinopereira@gmail.com

2 Disponível em http://www.gazetadopovo.com.br/vida-publica/politicos-sao-donos-de-15-das-radios-no-pr4yblfkq2j71gis214g8qals26. Acesso em 29.fev.2016.
} 
Em algumas cidades do interior, todas as rádios estão nas mãos de políticos. Na cidade de Ivaiporã existem três emissoras: a Uba Limitada, a Ivaiporã FM e a Rádio e Televisão Rotioner. A Uba tem entre os sócios o ex-governador Orlando Pessuti (PMDB). Regina Fischer Pessuti, mulher do ex-governador, é sócia da Ivaiporã FM e a Rotioner tem entre os proprietários Paula Pimentel e Luiz Guilherme Gomes Mussi. Ela, desde 2008, é mulher do deputado estadual Alexandre Curi (PMDB) e ele, sogro de Curi e suplente do senador Roberto Requião (PMDB). Além deles, o pai de Alexandre Curi, Aníbal Khury Júnior, é um dos donos da Rádio Poema, no município de Pitanga. Situação semelhante acontece na cidade de Guarapuava. Com pouco mais de 167 mil habitantes e 117 mil eleitores, duas tradicionais famílias políticas disputam os ouvintes. De um lado está o conselheiro do Tribunal de Contas do Estado Artagão de Mattos Leão, pai do deputado estadual Artagão de Mattos Leão Júnior. A família Leão é dona da rádio Difusora Guarapuava e da Emissora Atalaia. O próprio conselheiro do TC aparece no quadro societário da Difusora. A outra emissora tem como sócia a psicóloga Cleri Becher de Mattos Leão, mulher do conselheiro. Do outro, o prefeito Luiz Fernando Ribas Carli e a primeira dama do município, Ana Rita Slaviero Guimarães Carli, são sócios da rádio Guairacá de Guarapuava. Os dois são pais do ex-deputado Luiz Fernando Ribas Carli Filho, que renunciou ao mandato de deputado estadual depois de se envolver num acidente de trânsito que terminou com a morte de duas pessoas; e de Bernardo Carli, que assumiu uma cadeira na Assembleia Legislativa. Em Maringá, a lista de donos de emissoras de rádio confirma a força e o poder político da família Barros. Ricardo Barros é um dos donos da rádio Nova Ingá, ao lado do ex-deputado federal Benedito Cláudio Pinga Fogo de Oliveira. A rádio Difusora de Maringá tem entre os proprietários a ex-deputada federal e atual vice-governadora Cida Borghetti, mulher de Barros, e Gilberto Braz Palma, que é filho do ex-deputado estadual Divanir Braz Palma.

As grandes empresas de comunicação também são controladas por poucas famílias no Paraná.

A família Petrelli é dona da RIC Record, com 11 emissoras de TV, 3 portais de internet, 5 emissoras de rádio (Jovem Pan), 2 jornais e 2 editoras de revistas. A J Malucelli é dona da TV Bandeirantes Curitiba e Maringá, BandNews FM, CBN Curitiba, Jornal Metro e Rádio Globo Curitiba e Paranaguá. E a família Mussi Pimentel da Rede Mercosul de Comunicação. A família 
Massa Martinez do apresentador Ratinho e seu filho, o deputado e secretário de Beto Richa, Ratinho Junior (PSC), donos da Rede Massa, que domina o SBT no Paraná com 5 retransmissoras e tem a rádio Massa FM (7 por todo o estado).

Nosso estudo trata da família de Francisco Cunha Pereira Filho, por muito tempo o maior empresário de comunicações do Paraná. Seus herdeiros, junto com a família Lemanski, são donos do GRPCOM - Grupo Paranaense de Comunicação, que domina a RPC TV (oito emissoras de TV afiliadas à Rede Globo), os sites RPC TV, G1 Paraná, Globo Esporte Paraná, Paraná Online, os jornais Gazeta do Povo (o maior do Paraná), Jornal de Londrina, Gazeta Maringá e Tribuna, as rádios 98FM, Mundo Livre FM, Cultura FM e ainda empresas como ÓTV, HD View, Canal do Crédito e Zaag. Grupo comprou os jornais Tribuna do Paraná e o Estado do Paraná além do portal Paraná-Online, que pertenciam ao Grupo Paulo Pimentel. Este artigo objetiva fazer uma reconstrução histórica da família de Francisco Cunha Pereira Filho, pois ela forma uma grande rede de cumplicidades e mútuos benefícios entre diferentes poderes e instituições do Paraná.

\section{FAMÍLIA CUNHA PEREIRA}

Cunha Pereira é uma família extensa e tradicional de Minas Gerais. Dentre seus membros estão capitães de milícia, capitães de ordenança, fidalgos da Casa Real, Senadores, Procuradores, Juízes e Desembargadores.

Francisco Cunha Pereira, filho de Simão da Cunha Pereira e Eufrásia de Vasconcelos Cunha, nasceu no dia 13 de agosto de 1895, na cidade de Peçanha, no vale do Açassui, leste do estado de Minas Gerais. Bacharel pela Faculdade do Rio de Janeiro, colou grau no ano de 1918. Iniciou sua carreira na magistratura como juiz municipal em Clevelândia no interior do Paraná. Em 1924, foi removido para São José dos Pinhais. No mesmo ano, foi indicado pelo Tribunal de Justiça do Paraná para organizar o recém criado Juizado Privativo de Menores, do qual foi o primeiro juiz e onde permaneceu por 23 anos. Foi ainda, mentor de várias escolas e instituições de atendimento a menores no Paraná. Em Curitiba foi presidente do Tribunal do Júri e do Juizado de Casamentos. No dia 14 de fevereiro de 1947, foi nomeado para ocupar o cargo de desembargador. 
Exerceu a vice-presidência, de 1949 a 1952, e, pelo período de quatro anos exerceu o cargo de presidente do Tribunal Regional Eleitoral, tendo sido eleito pela primeira vez em 1955 e reeleito em 1957. No magistério, foi professor fundador e mais tarde diretor da Faculdade de Direito de Curitiba, de 1952 a 1977, tendo lutado em prol do reconhecimento da instituição pelo Ministério da Educação e da Cultura (MEC), obtido em 1954. Acumulou o cargo diretivo com a titularidade da cadeira de Direito Judiciário Penal onde recebeu o título de "Diretor Perpétuo".Aposentou-se, no cargo de desembargador, em 1966, após 40 anos de serviço público. Após sua aposentadoria, foi convidado pelo fundador do Banco Bamerindus, hoje extinto, para ser Conselheiro do Banco. É patrono do Fórum de Pinhais e do Fórum Eleitoral de Paranaguá. Faleceu aos 103 anos, no dia 17 de novembro de $1999^{3}$.

Francisco Cunha Pereira casou com Júlia do Amaral Ferreira, comumente chamada de Julinda, oriunda de uma das famílias mais tradicionais da Lapa. Nascida em 20/10/1899, seus pais eram os primos Josepha do Amaral Ferreira - irmã do ilustre lapeano Victor Ferreira do Amaral - e João Cândido Ferreira.

João Cândido Ferreira nasceu em 21 de abril de 1864, na Fazenda Taboão, propriedade de seu avô materno, o Comendador Gregório Antunes Maciel, localidade pertencente ao Município da Lapa. Filho do capitão João Cândido Ferreira e de dona Anna Leocádia Ferreira, descendia de antigos troncos curitibanos e era parente próximo de Diogo Antônio Feijó, regente do império. Depois de passar pelo afamado Colégio Sagrado Coração de Jesus, de Sorocaba, São Paulo, seguiu o caminho de tantos jovens talentosos da época: em 1883, foi estudar no Rio de Janeiro, onde cursou humanidades no Colégio Alberto Brandão e, com brilho, em 1888, aos 24 anos, formou-se médico pela Faculdade de Medicina da então capital federal. Depois de formado, retornou à sua terra natal para exercer a profissão de médico, estabelecendo-se com consultório no centro daquela cidade. Ainda jovem ingressou na política local, sendo prefeito municipal da cidade da Lapa, de 1892 a 1896, durante o Cerco da Lapa, período marcado pela Revolução Federalista, ao qual foi nomeado médico diretor do hospital de sangue em 1894, quando a cidade foi ocupada durante 27 dias pelas tropas maragatas chefiadas pelo caudilho castelhano Gumercindo Saraiva, combatidas

\footnotetext{
${ }^{3}$ Ver a biografia do Tribunal de Justiça do Paraná: https://www.tjpr.jus.br/desembargadores-tjpr-museu
} 
por outro lado pelo coronel Antônio Ernesto Gomes Carneiro, enviado ao Paraná pelo marechal Floriano Peixoto para conter o avanço das tropas deste rumo à capital federal, Rio de Janeiro.

Após a revolução, pelo Partido Republicano, João Cândido foi eleito deputado estadual em 1896, em 1901 deputado federal e em 1903 vice-presidente do estado, vindo a assumir a presidência por diversas vezes na ausência do titular, Vicente Machado da Silva Lima, por motivo de tratamento médico e mais tarde por ocasião de sua morte em 1907. Como presidente do estado, realizou importantes feitos em relação à educação e à saúde, fundando a Escola de Agronomia do Paraná e reorganizando os sistemas de saúde pública e de ensino. João Cândido fundou e sustentou junto de seu primo e cunhado o também médico Victor Ferreira do Amaral e Silva a primeira Universidade do Paraná, contribuindo com a publicação de vasta obra bibliográfica na medicina nacional. Também foi presidente da Sociedade de Medicina do Paraná e editor do periódico ParanáMedico. Na década de 1920, João Cândido participou do movimento eugênico brasileiro, dialogando com as teorias neo-hipocrática e neo-lamarckistas. Junto da Faculdade de Medicina do Paraná iniciou uma luta contra a sífilis, tuberculose e alcoolismo. Faleceu em Curitiba em 20 de fevereiro de 1948, após a morte de um filho chamado Murilo, com quem tinha muita afinidade. Com Josepha do Amaral Ferreira teve os filhos Alceu, Leônidas, João Cândido, Murilo, Agenor, e uma única mulher, Júlia, gêmea de seu irmão Celso.

Júlia do Amaral Ferreira casou com Francisco Cunha Pereira e tiveram quatro filhos.

Lincoln Ferreira Cunha Pereira nasceu em 13/02/1928 em Curitiba, advogado, já foi deputado estadual no Paraná e Presidente da Associação Comercial de São Paulo. Casou-se com Maria Thereza Carvalho Ribeiro com quem teve cinco filhos: Lincoln da Cunha Pereira Filho (vicepresidente da associação comercial de São Paulo), João Paulo (engenheiro com especialização nos Estados Unidos), Marcelo Ribeiro da Cunha Pereira, André (piloto de corridas automobilísticas) e Ricardo Ribeiro da Cunha Pereira (diretor da Euro Import, concessionária de carros importados).

Maria Julinda Ferreira Cunha Pereira nasceu em 06/07/1931 em Curitiba. Reside na Paraíba, é viúva de um engenheiro de açúcar de João Pessoa, o Francisco Leocádio Ribeiro Coutinho. Tem sete filhas, todas com o segundo nome de sua mãe: Ana Julinda Pereira, Berenice 
Julinda, Flávia Julinda, Débora Julinda Coutinho, Cláudia Julinda Coutinho, Edla Julinda e Grace Julinda.

João Cândido Ferreira Cunha Pereira nasceu em 14/11/1929 em Curitiba, PR. Fez curso primário no grupo escolar Barão do Rio Branco, curso ginasial e científico no Colégio Santa Maria, formado em Medicida pela UFPR em 1953. Foi conselheiro do Tribunal de Contas do Paraná (X1999).

Casou-se com Cleony Pinto Pereira com quem teve três filhos, todos consultores técnicos no Tribunal de Contas. João Cândido da Cunha Pereira Filho, formado em Direito pela Universidade Federal do Paraná, foi consultor técnico do Tribunal de Contas onde é atualmente aposentado, tem escritório de advocacia em Curitiba, casado com Maria da Graça Pacheco, consultora técnica do Tribunal de Contas. José Francisco da Cunha Pereira foi consultor técnico do TC, falecido em 26 de junho de 2013. Eduardo Luiz Pinto da Cunha, consultor técnico e atualmente aposentado pelo Tribunal de Contas. Isso é, enquanto foi conselheiro, João Cândido colocou todos os filhos no Tribunal de Contas. Além disso, outros servidores do TC também são parentes ou ligados diretamente ao conselheiro aposentado, João Cândido Cunha Pereira: Cleusa Juliato, Alexandre Juliato Pallu, Priscila Mara Pallu, Luciana de Fátima Nogueira Nascimento e Antônio Nunes Nogueira ${ }^{4}$.

Francisco Cunha Pereira Filho nasceu em Curitiba, em 7 de dezembro de 1926. Estudou no Grupo Escolar Barão do Rio Branco e no Colégio Santa Maria. Frequentou aulas noturnas no Colégio Paranaense, onde estavam os melhores professores daquele tempo. Apesar de a família ter diversos médicos, por influência do pai prestou vestibular para Direito na Universidade Federal do Paraná. Nesta época já frequentava o Clube Curitibano, a Sociedade Duque de Caxias e o Country Club. Formou-se em 1949, tendo atuado no Diretório Central de Estudantes. Abriu um escritório de advocacia com o colega João Severino de Oliveira Perez chamado Co-Jurídico onde realizaram

... representações de sapatos, tênis e todos os produtos típicos do Nordeste. No escritório se fazia preparação de papéis de casamento, requerimentos de isenção de multas por falta de registros de nascimento, civis e de pequenas questões de locações. Eu ainda fiz um estágio no escritório do advogado Hélio Setti, atuando em todas as áreas. Depois de formado,

\footnotetext{
${ }^{4}$ Ruth Bolognese. A Grande Família do Tribunal de Contas. Folha de Londrina. 18 de março de 2007.
} 
montei o meu escritório de advocacia, desta vez, em parceria com o meu irmão Lincoln, que já estava concluindo o curso de Direito. Nesse momento, achei que deveria me impor como advogado e parti para a experiência do Tribunal do Júri. Minha estreia foi com o Salvador de Maio, um advogado famoso. O promotor era o Maranhão, que foi desembargador. Absolvemos o acusado. Foi a minha primeira vitória. Trabalhei em casos muito importantes, como o de Carolina Taborda Ribas, acusada de ter assassinado o namorado da filha. Neste caso, trabalhei na acusação. Mas eu prefiro defender. Fiz mais de cem júris, atuando na defesa. Trabalhei por quatro anos no processo que respondeu Moysés Lupion ao deixar o governo do Paraná. Na defesa dele também estavam o professor de Direito Penal Laertes Munhoz, e o ministro Evandro Lins e Silva. O Lupion foi absolvido. No Tribunal do Júri eu obtive bons rankings ${ }^{5}$.

Em 1962, Cunha Pereira abandonou uma bem-sucedida carreira como criminalista para ingressar no jornalismo com a compra a Gazeta do Povo de Oscar Joseph de Plácido e Silva em sociedade com o seu colega da UFPR, Edmundo Lemanski. Tempos depois assumiu a TV Paranaense, canal 12, firmando-se como empresário do campo das comunicações. Sua sorte começou a mudar em 31 de março de 1964, data do golpe militar que depôs o presidente João Goulart. A Gazeta do Povo tornou-se uma defensora fanática do regime e sua fidelidade à ditadura militar foi recompensada com generosas verbas publicitárias do governo federal para a Gazeta e também para a TV Paranaense (canal 12) que contava com a participação acionária do empresário Roberto Marinho. A sociedade com a família Marinho foi desfeita apenas em 2002, quando o Grupo paranaense assumiu a totalidade da emissora. Nos anos seguintes foram montadas ou compradas mais sete emissoras de televisão, cobrindo todas as regiões do Estado. Era o ocupante da cadeira de número 18 da Academia Paranaense de Letras, sucedendo Manoel de Lacerda Pinto, em 1974. Era conselheiro do Atlético Paranaense.

Francisco Cunha Pereira Filho casou com Terezinha Döring, gaúcha de Porto Alegre criada em Curitiba, na Rua Saldanha Marinho, na altura da Praça Espanha. Terezinha estudou no Colégio Sion, fazia estudos de piano e ensaios de balé no Curso. Em dezembro de 1957 - exatos 12 meses depois de conhecer Francisco no Curitibano - foi eleita o "Broto do Ano" pela revista Alta Sociedade. Em 1960, entrou para a Escola de Música e Belas Artes do Paraná (Embap), integrando uma das gerações mais originais já passadas pelo curso de Pintura da faculdade. Seus

\footnotetext{
5 Disponível em http://www.gazetadopovo.com.br/especiais/fcpf/icone-da-imprensa-paranaensebhfohbxiplpo0fwdvz6zmn9se. Acesso em 29.fev.2016.
} 
contemporâneos eram João Osório Brzezinski e Fernando Calderari, para citar dois. Casou-se com Francisco dia 28 de dezembro, na Igreja São Francisco de Paula em 1963. Depois do casamento Terezinha abandonou a pintura e se recolheu à educação dos quatro filhos do casal - Francisco Neto, Guilherme, Ana Amélia e Cristina 6 .

Em se tratando dos irmãos Guilherme Cunha Pereira e Ana Amélia Cunha Pereira Filizola consta que os dois trataram de afastar outros dois irmãos - Francisco Cunha Pereira Neto e Cristina Cunha Pereira - do comando das 16 empresas do grupo. Há dois processos que correm sobre segredo de justiça. No caso de Cristina Cunha Pereira, o processo ter a ver com o seu ex-marido que pleiteava participar das decisões da empresa. Casada, com quatro filhos, Cristina foi forçada a pedir divórcio e o marido foi expulso de casa, à força por seguranças à mando da família ${ }^{7}$.

Outro caso, trata-se de Francisco Cunha Pereira Neto, o filho predileto do patriarca Francisco Cunha Pereira. Pereira Neto estudou física na Alemanha Oriental e se formou. Rompeu com a família, casou e passou a morar com a companheira Valéria Colombo, de forma reclusa, num apartamento em Curitiba. A família contrariada sequestrou Pereira Neto á força, acusou a então companheira de "oportunista" e a ameaçou. Ela, por sua vez, entrou com processo na Justiça, quem corre sobre segredo.

Guilherme Döring Cunha Pereira, mestre e doutor pela Faculdade de Direito da USP e diretor da Rede Paranaense de Comunicação. Membro da Opus Dei. Recebeu em 2014 a Ordem do Pinheiro, a mais alta honraria do estado do Paraná. A homenagem foi entregue pelo governador Beto Richa, no Palácio Iguaçu.

Ana Amélia Cunha Pereira Filizola, nascida em 04/03/1967, é formada em Comunicação Social pela UFPR, com MBA pela FGV e mestre em Jornalismo pela Faculdade de Comunicação da Universidade de Navarra. Começou sua carreira profissionais como repórter do caderno de Turismo da Gazeta do Povo. Foi editora do Caderno G. Em 1997 deixa a redação da Gazeta para atuar na área administrativa. Membro do Rotary Club. Casou em 1989 com Ricardo Filizola,

\footnotetext{
6 Disponível em http://www.gazetadopovo.com.br/especiais/fcpf/a-quem-terezinha-doring-deu-a-maobhfq4174nmqew6bzanyocbgb2. Acesso e 29.fev.2016.
}

\footnotetext{
${ }^{7}$ Disponível em http://www.istoe.com.br/reportagens/38868_CADE+ROMEU+. Acesso em 29.fev.2016.
} 
engenheiro civil formado pela PUCPR, chefe de cozinha e atualmente é sócio da La Cocina Gastronomia e Eventos.

\section{BRIEF GENEALOGY CUNHA PEREIRA FAMILY}

\section{ABSTRACT}

The purpose of this article is to describe and analyze the social and political profile of the members of the family of Francisco Cunha Pereira Filho, president of the People's Gazette newspaper. To this end, we present description of the generations of the family confirming the presence of its members in Paraná public sphere. This research was aimed to follow up in the study of the genealogies of Paraná ruling class.

Key-words: Genealogy. Business Communication. Power. 